\title{
In the complex family of heat stress transcription factors, HsfA1 has a unique role as master regulator of thermotolerance in tomato
}

\author{
Shravan Kumar Mishra, Joanna Tripp, Sybille Winkelhaus, Bettina Tschiersch, ${ }^{1}$ Klaus Theres, ${ }^{2}$ \\ Lutz Nover, ${ }^{3}$ and Klaus-Dieter Scharf
}

Biocenter of the Goethe University, D-60439 Frankfurt am Main, Germany

\begin{abstract}
We generated transgenic tomato plants with altered expression of heat stress transcription factor HsfA1. Plants with 10-fold overexpression of HsfA1 (OE plants) were characterized by a single HsfA1 transgene cassette, whereas plants harboring a tandem inverted repeat of the cassette showed cosuppression (CS plants) by posttranscriptional silencing of the HsfA1 gene connected with formation of small interfering RNAs. Under normal growth conditions, major developmental parameters were similar for wild-type (WT), OE, and CS plants. However, CS plants and fruits were extremely sensitive to elevated temperatures, because heat stress-induced synthesis of chaperones and Hsfs was strongly reduced or lacking. Despite the complexity of the plant Hsf family with at least 17 members in tomato, HsfA1 has a unique function as master regulator for induced thermotolerance. Using transient reporter assays with mesophyll protoplasts from WT tomato, we demonstrated that plasmid-encoded HsfA1 and HsfA2 were well expressed. However, in CS protoplasts the cosuppression phenomenon was faithfully reproduced. Only transformation with HsfA2 expression plasmid led to normal expression of the transcription factor and reporter gene activation, whereas even high amounts of HsfA1 expression plasmids were silenced. Thermotolerance in CS protoplasts was restored by plasmid-borne HsfA2, resulting in expression of chaperones, thermoprotection of firefly luciferase, and assembly of heat stress granules.
\end{abstract}

[Key Words: Posttranscriptional gene silencing; heat stress transcription factors; chaperones; siRNA; tomato; thermotolerance]

Received February 25, 2002; revised version accepted May 3, 2002.

Heat stress transcription factors (Hsfs) are the terminal components of a signal transduction chain mediating the activation of genes responsive to heat and a large number of chemical stressors. Stress-induced gene expression leads to the rapid accumulation of heat stress proteins (Hsps) which as molecular chaperones play a central role not only in protection against stress damage but also in folding, intracellular distribution and degradation of proteins (Agashe and Hartl 2000; Ellis 2000; Jolly and Morimoto 2000; Richter and Buchner 2001). Promoters of eukaryotic heat stress (hs)-inducible genes share common Hsf recognition elements (HSEs) with the palindromic consensus sequence (AGAAn)(nTTCT) (Pelham 1982; Pelham and Bienz 1982; Nover 1987). Similar to

Present addresses: ${ }^{1}$ SunGene GmbH \& Co., Corrensstr.3, D-06466 Gatersleben, Germany; ${ }^{2}$ MPI für Züchtungsforschung, Carl-von-Linne-Weg 10, D-50829 Köln, Germany.

${ }^{3}$ Corresponding author.

E-MAIL nover@cellbiology.uni-frankfurt.de; FAX 49-69-798-29286. Article and publication are at http://www.genesdev.org/cgi/doi/10.1101/ gad.228802. other transcription factors, Hsfs have a modular structure with an N-terminal DNA-binding domain characterized by a central helix-turn-helix motif, an adjacent oligomerization domain with a bipartite heptad pattern of hydrophobic amino acid residues (HR-A/B region), and sequence motifs essential for nuclear import and export (NLS, NES; Wu 1995; Morimoto 1998; Heerklotz et al. 2001; Nover et al. 2001). In many cases, the C-terminal activation domains are characterized by short peptide motifs (AHA motifs) shown to be crucial for the activator function (Döring et al. 2000).

Sequencing of the Arabidopsis genome revealed a unique complexity of the Hsf family with 21 members, in contrast to yeast and Drosophila with one Hsf and vertebrates with four Hsfs (Wu 1995; Nover et al. 2001). From analyses of expressed sequence tag (EST) libraries, it is evident that the size of the Hsf family is comparable also in other plants, with 17 Hsfs thus far identified from tomato ESTs (Nover et al. 2001). By structural characteristics and phylogenetic comparison, plant Hsfs were assigned to three classes. In Arabidopsis, there are 15 
members in class A, five members in class $B$, and one in class $C$. Most striking for the discrimination of the three classes are peculiarities of the HR-A/B regions. Similar to all nonplant Hsfs, the HR-A/B regions of class B Hsfs are compact, with seven amino acid residues separating the HR-A and B parts, whereas class A and class C Hsfs have extended HR-A/B regions due to an insertion of 21 (class A) and seven (class C) additional amino acid residues (Nover et al. 2001). The significance of these extended oligomerization domains for the oligomerization behavior and function of Hsfs is not yet clear. Another plant-specific feature with probably important consequences for details of the stress response is the fact that many Hsfs are hs-inducible proteins themselves (Scharf et al. 1990, 1998; Nover et al. 2001); for example, in tomato HsfA1 is constitutively expressed, whereas Hsfs $\mathrm{A} 2$ and $\mathrm{B} 1$ are hs-inducible proteins.

To study the role of individual Hsfs in their native background, we generated stable genetic lines of tomato with altered expression of HsfA1, HsfA2, or HsfB1 by Agrobacterium-mediated integration of corresponding sense and antisense transgenes. Analyses of the transgenic plants demonstrate that HsfA1 has a unique role as master regulator for the synthesis of Hsfs A2 and B1 as well as Hsps. Posttranscriptional silencing of the HsfA1 gene also causes severe defects in thermotolerance and plant development at elevated temperatures.

\section{Results}

Characterization of transgenic tomato lines with overexpression and cosuppression of HsfA1

Using Agrobacterium-mediated gene transfer, tomato leaf discs (Lycopersicon esculentum cv. Moneymaker) were transformed with Ti plasmid-derived vectors encoding tomato heat stress transcription factor HsfAl and neomycin phosphotransferase for selection. In the vector used for transformation, the cDNA cassette encoding HsfAl is positioned next to the right border (RB) of the T-DNA, whereas the NPTII cassette is linked to the left border (LB, see example in Fig. 1A). Since the transfer of T-DNA occurs in a polar fashion starting at the right border (Becker et al. 1992; Sheng and Citovsky 1996), most regenerates showing kanamycin resistance also harbored the Hsf encoding cassette. Kanamycin-resistant transgenic shoots were regenerated, rooted, and finally transferred to the greenhouse. Seedlings derived from the $\mathrm{T}_{\mathrm{O}}$ generation were sprayed with kanamycin solution to discriminate between sensitive (wild-type) and resistant, that is, transgenic plants. The latter were further cultivated, seeds were harvested ( $\mathrm{F}_{1}$ generation), and the procedure was repeated until stable, homozygous lines were obtained.

Starting with the $F_{1}$ progenies, $\operatorname{Kan}^{\mathrm{r}}$ plants were analyzed by Southern and immunoblot analyses to monitor the segregation of the transgene(s) and expression levels of HsfA1. Among the 51 independent $\operatorname{Kan}^{\mathrm{r}}$ primary plants, one was identified (A1-S17) as containing three transgene cassettes. Progeny of this $\mathrm{T}_{0}$ plant segregated into three independent sublines. The results of the Southern, Northern, and immunoblot analyses of $\mathrm{F}_{3}$ progenies are shown in Figure 1B-D. One subline containing a single transgene cassette (T1) showed an $\sim 10$ fold increased level of HsfA1 (overexpression line, OE), whereas the two other sublines containing two (T2 and $\mathrm{T} 3$, cosuppression line CS2) and three (T1, T2, and T3, cosuppression line CS 3) transgene cassettes in their genome had no detectable HsfA1. Compared to the wild type (WT), plants of all three transgenic lines showed normal growth and development as judged from size of the plants, time of flowering, fruit setting and ripening, as well as number of seeds in the fruits and seed germination (data not shown).

As a consequence of the altered levels of HsfA1 in the $\mathrm{OE}$ and CS lines, the expression patterns of hs-inducible genes were markedly changed. This was analyzed by Northern blot (Fig. 1C) and immunoblot analyses (Fig. 1D) using samples from young leaves and pericarp of green fruits under control (lane C) and heat stress (lane $\mathrm{H})$ conditions. In WT and OE plants, hs-induced synthesis of HsfA2, HsfB1, Hsp17-CI, and Hsp104 was clearly detectable, and the strongly increased HsfAl levels in the OE plants was connected with two- to threefold higher levels of HsfA2, HsfB1, and Hsp17-CI in the leaves and hs-independent expression of HsfA2, Hsp17$\mathrm{CI}$, and Hsp104 in the pericarp. In contrast, hs-induced synthesis of HsfA2, HsfB1, and Hsp17-CI was markedly reduced or even lacking in the CS2 and CS3 cosuppression plants. The results from the Northern and immunoblots were very similar except for the Hsc70/Hsp70 complex. The antibody did not allow discrimination between constitutive and heat stress-inducible isoforms of the protein (Fig. 1D). However, using gene-specific probes for detection of the Hsp70 encoding mRNA, the results of the Northern blot clearly indicated that expression of Hsp70 in CS plants was also strongly reduced (Fig.1C).

Also of interest are the subtle but reproducible differences in the HsfA1-dependent expression of HsfA2 and Hsps observed between samples from CS2 and CS3 plants. Although the silencing effect in CS3 plants is strong enough to overcome the 10 -fold increased expression of HsfA1 as a result of the T1 transgene cassette, residual HsfA1 in leaves might allow some hs-inducible expression of HsfA2 and Hsp17-CI (Fig. 1D). This effect was not observed in pericarp of green fruits, indicating that the strength of the silencing effect was dependent on the tissue investigated. This was particularly striking for the expression of Hsp104, which was only slightly reduced in leaves, but totally lacking in pericarp (Fig. 1D).

The expression analyses (Fig. 1C,D) indicate a unique role of HsfA1 as a constitutively expressed member of the tomato Hsf family. We sought to establish whether the altered levels of HsfAl in OE and CS compared to WT plants are also detectable by electrophoretic mobility shift assays. Using extracts of nuclear proteins and Hsf-specific oligonucleotides as probes, an hs-inducible 
A: T2-T3 tandem inverted repeat

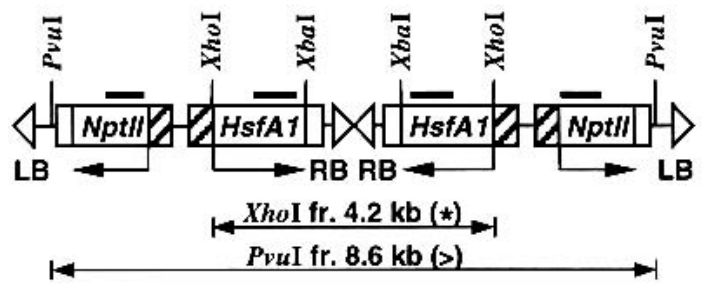

B: Southern blot

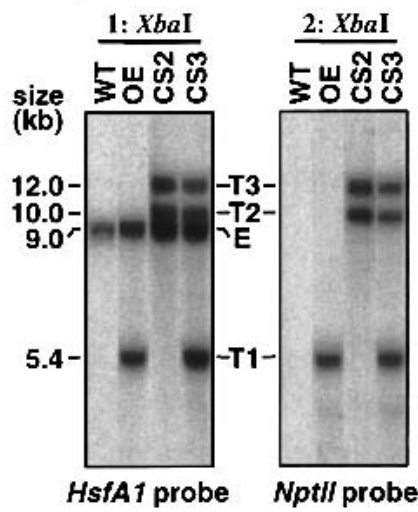

3: $P v u \mathrm{I}$ 4: XhoI
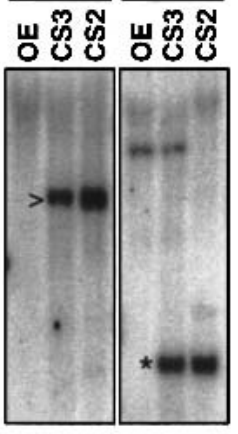

HsfA1 probe

\section{C: Northern blot}

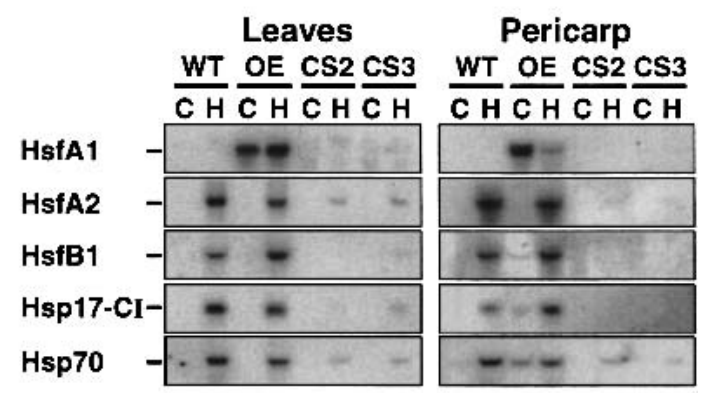

D: Immunoblot

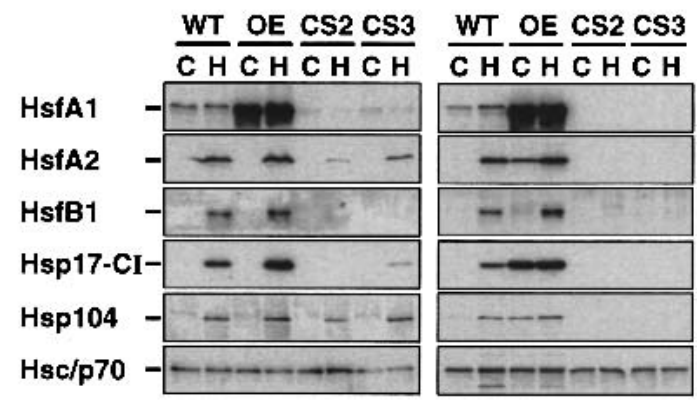

Figure 1. Characterization of transgenic tomato lines with overexpression or cosuppression of HsfA1. (A) Block diagram of inverted repeat of two transgene cassettes in the CS2 and CS3 lines. Diagnostic cleavage sites for restriction enzymes XbaI, XhoI, and PvuI are indicated at the top. Bars mark positions of probes used for Southern blot analysis. Promoter regions of neomycin phosphotransferase $(N p t I I)$ and heat stress transcription factor HsfA1 cassettes are represented by hatched boxes. (LB, RB) Left and right borders of T-DNA. Double-headed arrows mark diagnostic PvuI $(>)$ and XhoI $\left(^{*}\right)$ fragments detected in B3 and B4 as indicator of the inverted repeat. $(B)$ Southern blot analysis using the indicated DIG-labeled NptII and HsfA1-specific probes. Genomic DNA from wild-type (WT), HsfA1 overexpression (OE), and cosuppression (CS) plants was digested with XbaI and XhoI or PvuI. Note that all three transgene cassettes (T1, T2, T3) contain both coding parts of the cassette used for transformation (B1 vs. B2). The positions of the two T2 and T3 cassettes with $8.6 \mathrm{~kb}$ for the $P v u \mathrm{I}(>)$ and $4.2 \mathrm{~kb}\left({ }^{*}\right)$ for the XhoI-digested DNA document the integration of the tandem inverted repeat into the DNA of CS2 and CS3 plants (B3 and B4). An additional $12 \mathrm{~kb}$ Xhol fragment in the DNA samples from OE and CS3 plants represents the T1 transgene cassette (B4). (C) Northern blot analysis of RNA samples prepared from heat-stressed (H) or control (C) leaves and fruit pericarp. For heat-stressed leaves, whole plants were incubated for $1 \mathrm{~h}$ at $45^{\circ} \mathrm{C}$, followed by a recovery for $2 \mathrm{~h}$ at $25^{\circ} \mathrm{C}$ before young leaves were harvested and frozen in liquid nitrogen. For RNA from heat-stressed pericarp, mature green fruits were incubated for $4 \mathrm{~h}$ at $42^{\circ} \mathrm{C}$ and then frozen. mRNAs were detected with the indicated Dig-labeled probes. Ribosomal RNA stained with methylene blue was used to verify equal loading of the lanes (data not shown). (D) Immunoblot analyses of Hsf and Hsp expression. Proteins were prepared from the same plant materials as described for the Northern blots. The indicated proteins were detected by the antibodies described in Materials and Methods.

shift of the radiolabeled HSE3 oligonucleotide into an Hsf-specific DNP complex was observed in samples incubated with extracts from WT plants (Fig. 2, cf. lanes 2 and 3). However, no DNP complex could be detected in any sample from either CS plant, even after very long exposure of the autoradiograph (Fig. 2, lanes 4-7). In contrast, samples from OE plants already showed a weak signal for DNP complex formation under control conditions, and this signal was strongly enhanced in samples from heat-stressed plants (Fig. 2, lanes 8 and 9). As expected, the mobility shift of the radiolabeled probe was successfully competed by a 50 -fold excess of unlabeled wild-type HSE3c but not by mutant HSE3c (Fig. 2, lanes 10 and 11). The results in Figure 2 support our conclusions about HsfAl as the essential regulator for hs-induced gene expression in tomato.
Integration of the tandem inverted repeat of the transgene cassettes T2 and T3 in CS plants causes formation of small interfering RNA (siRNA)

The segregation pattern and Southern blot analysis of the three independent sublines derived from the single $T_{0}$ plant (Fig. 1B) indicated the integration of three cassettes, with two of them (T2 and T3) being tightly linked on one chromosome. Evidently, the coexistence of the $\mathrm{T} 2$ and $\mathrm{T} 3$ transgene cassettes caused the cosuppression effect, that is, silencing not only of the endogenous HsfA1 gene in CS2 plants but also of the strongly expressed T1 transgene in the CS3 plants. To analyze the linkage of the T2 and T3 cassettes in more detail, we digested genomic DNA with restriction enzymes $P$ vuI and $X h o I$ and detected signals with an HsfA1-specific 


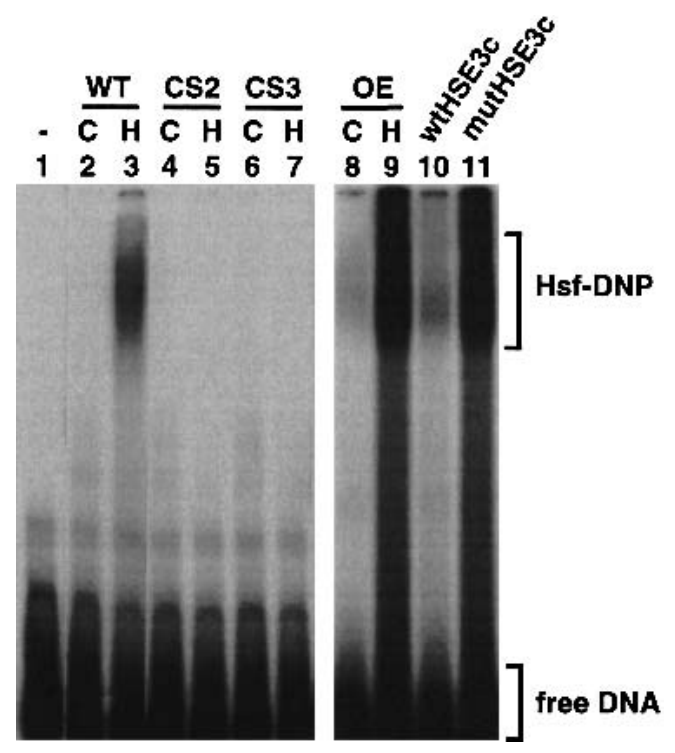

Figure 2. Electrophoretic mobility shift assays with nuclear extracts from tomato leaves. Eight-week-old greenhouse plants were heat-stressed for $1 \mathrm{~h}$ to $45^{\circ} \mathrm{C}(\mathrm{H})$ or kept at $25^{\circ} \mathrm{C}(\mathrm{C})$ before young leaves were harvested for preparation of nuclei (see Materials and Methods). Lanes 2-9, radiolabeled HSE oligonucleotide incubated with the indicated nuclear extracts from WT, CS2, CS3, and OE plants. For the competition assay, the extract from heat-stressed OE plants was incubated with the labeled HSE3 plus a 50-fold excess of wild-type (wtHSE3c) or mutant oligonucleotide (mutHSE3c) in unlabeled form (lanes 10 and 11). Lane 1, sample without protein extract. Samples 1 to 7 and 8 to 11 were run in separate gels. Film exposure was $5 \mathrm{~d}$ for samples 1 to 7 and $1 \mathrm{~d}$ for samples 8 to 11 .

probe (Fig. 1B, panels 3 and 4). The results clearly showed that the T2 and T3 cassettes form a tandem inverted repeat. The $8.6 \mathrm{~kb} P v u \mathrm{I}$ fragment (Fig. 1B, open arrowhead) and the $4.2 \mathrm{~kb}$ XhoI fragment (asterisk) corresponded to the expected cleavage pattern (double-headed arrows in the block diagram in Fig. 1A).

Next, we wanted to determine whether formation of small interfering RNAs (siRNAs) was responsible for the strong cosuppression effect observed in CS2 and CS3 plants containing the inverted repeat of the $H s f A 1$ sense cassettes in their genomes. We prepared soluble RNAs from young leaves of WT, OE, CS2, and CS3 plants, separated them on denaturing polyacrylamide/urea gels, and detected putative siRNA by RNA blot analysis using radiolabeled HsfA1-specific sense (Fig. 3A) and antisense riboprobes (Fig. 3B). In samples of the two types of CS plants, both riboprobes detected small RNAs of about 21 nucleotides which were lacking in samples from WT and OE plants. As size marker and hybridization control, we used 23-mers of ribooligonucleotides derived from the 5' region of the DNA binding domain of HsfA1. The control sense oligonucleotide gave a weaker signal with the antisense riboprobe (Fig. 3B, asterisk), because the oligonucleotide corresponds to the end of the $\sim 1.8 \mathrm{~kb}$ in vitro transcript. But as expected, this deficit in the signal intensity was not observed for the siRNAs, which repre- sent a mixture of RNAs covering the whole range of the HsfA1 mRNA.

\section{HsfA1 cosuppression plants are highly heat-sensitive}

What are the effects of the lacking synthesis of hs-inducible Hsfs A2 and B1 and Hsps on the growth and development of CS plants under stress conditions? To explore this question, we exposed 6-wk-old greenhouse plants in a climate chamber to either 1 -h heat treatment at $45^{\circ} \mathrm{C}$ followed by $1 \mathrm{~h}$ at $25^{\circ} \mathrm{C}$ or to $1 \mathrm{~h}$ at $45^{\circ} \mathrm{C}$ followed by 1 $\mathrm{h}$ at $51^{\circ} \mathrm{C}$. During the hs treatment, sufficient water supply was guaranteed. Control plants were maintained at $25^{\circ} \mathrm{C}$ throughout. Photographs of the plants were taken after another $14 \mathrm{~d}$ of growth in the greenhouse (Fig. 4A). The results documented that the CS3 plants were very heat-sensitive. Even exposure for $1 \mathrm{~h}$ at $45^{\circ} \mathrm{C}$ ambient temperature was lethal, whereas WT and OE plants were not visibly affected in their development. The CS2 and CS3 plants gave similar results. Only the more severe treatment of $1 \mathrm{~h}$ at $45^{\circ} \mathrm{C}$ followed by $1 \mathrm{~h}$ at $51^{\circ} \mathrm{C}$ revealed a difference between WT and OE plants. The former were strongly damaged but slowly recovered by forming lateral shoots, whereas the latter were only slightly delayed in their growth. Results were similar with germinating seedlings (data not shown).

To complement these results with vegetative plants, we harvested mature green fruits from WT, OE, and CS3 plants (sample 1 in Fig. 4B) and investigated the influence of a high-temperature treatment $\left(48 \mathrm{~h}\right.$ at $\left.42^{\circ} \mathrm{C}\right)$ on their ripening at $25^{\circ} \mathrm{C}$ in the dark. For comparison, con-
A: Sense probe

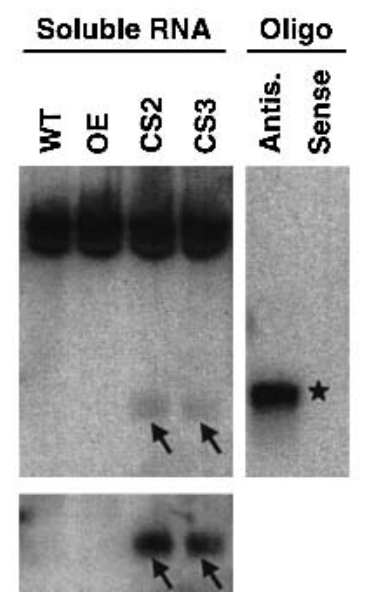

\section{B: Antisense probe}

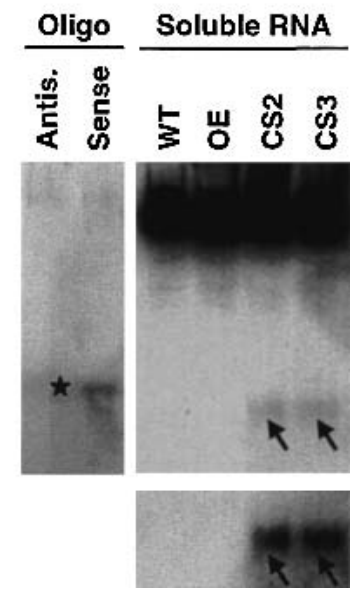

Figure 3. Detection of siRNA in CS plants. Soluble RNA fractions from leaves of WT, OE, and CS plants were separated on $15 \%$ denaturing polyacrylamide gels, blotted on nylon membranes, and hybridized with $H s f A 1$-specific sense $(A)$ and antisense riboprobes $(B)$. For the control, 23-mers of sense and antisense ribooligonucleotides derived from the DNA binding domain of HsfAl were run on the same gels (positions indicated by asterisks). Arrows point to the siRNA bands in the CS2 and CS3 samples. The inserts at the bottom of $A$ and $B$ represent longer exposures of the autoradiograph (only siRNA regions shown). 


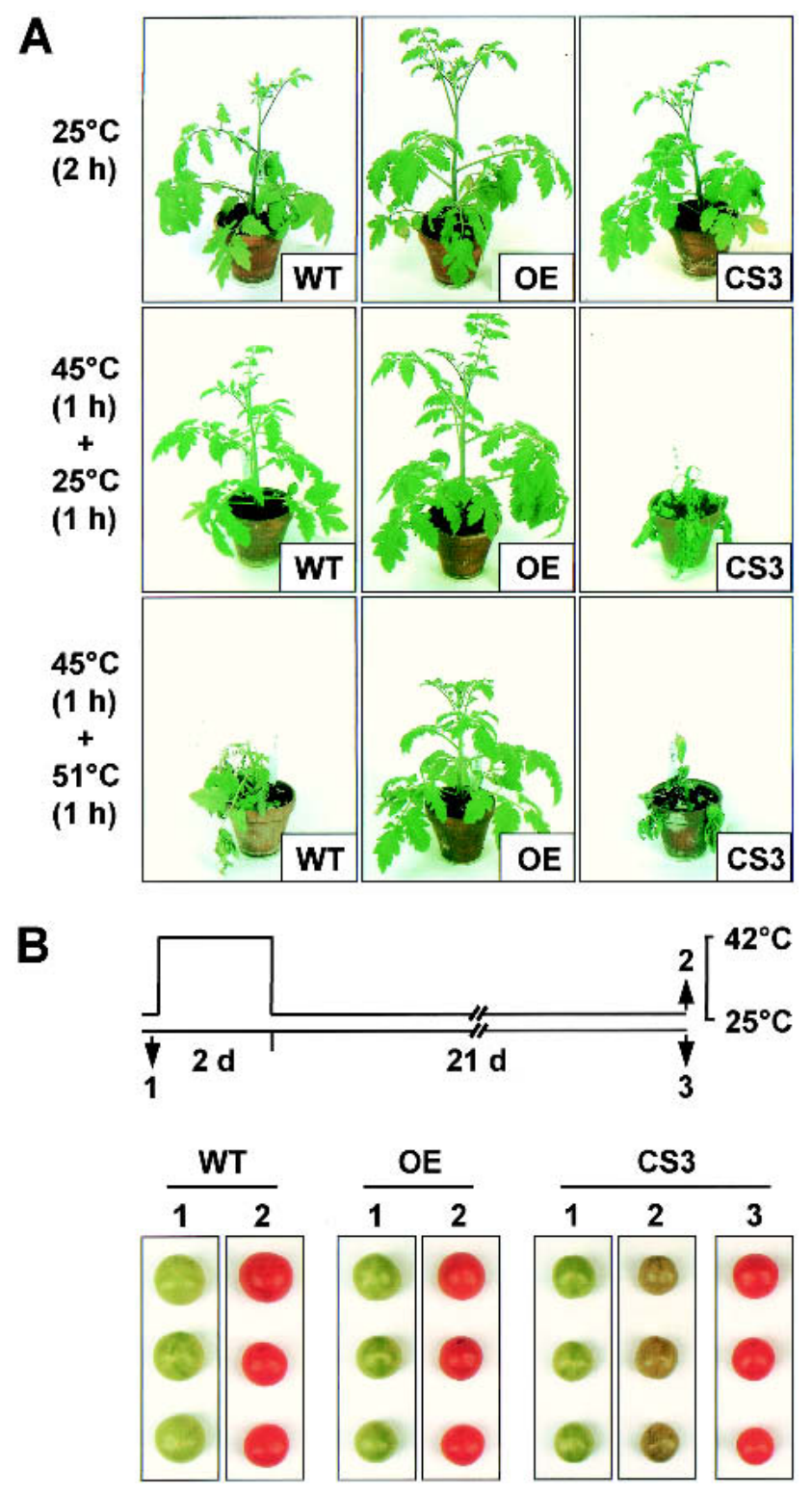

Figure 4. Thermotolerance of young plants and fruits. $(A)$ Sixwk-old plants from the greenhouse were subjected to the indicated 2-h treatments in a climate chamber: $2 \mathrm{~h}$ at $25^{\circ} \mathrm{C}$, or $1 \mathrm{~h}$ at $45^{\circ} \mathrm{C}$ plus $1 \mathrm{~h}$ at $25^{\circ} \mathrm{C}$, or $1 \mathrm{~h}$ at $45^{\circ} \mathrm{C}$ plus $1 \mathrm{~h}$ at $51^{\circ} \mathrm{C}$. Photographs were taken after 14-d growth in the greenhouse under normal temperature conditions. $(B)$ Mature green fruits were harvested (sample 1), incubated for $2 \mathrm{~d}$ at $42^{\circ} \mathrm{C}$ (sample 2), and then kept in the dark for $21 \mathrm{~d}$ (see pictograph at top of Fig. $3 B$ ). Fruits from WT and OE plants underwent normal ripening, whereas fruits from CS3 plants were severely damaged by the hs treatment. For control, sample 3 of CS3 fruits was allowed to ripen under the same conditions but without hs treatment.

trol fruits from all three types of plants were always kept at $25^{\circ} \mathrm{C}$ in the dark without preceding heat treatment (see pictograph at top of Fig. 4B). Within $23 \mathrm{~d}$, the fruits underwent normal ripening connected with the characteristic lycopene synthesis responsible for the generation of the red color of the fruits (shown only for CS3 fruits, sample 3). The heat treatment had no visible effects on the post-harvest ripening of fruits from WT and OE plants (sample 2). In contrast, the ripening program in fruits from CS3 plants was completely blocked by the heat treatment. The pericarp was visibly damaged and did not show any lycopene synthesis (Fig. 4B, CS3, sample 2). Evidently, the strongly reduced HsfA1 expression levels in CS plants caused a complete lack of inducible thermotolerance and a marked heat sensitivity at all developmental stages. We also generated comparable transgenic plants with defects in the expression of HsfA2 and HsfB1. In no case did we observe similar sensitivity to mild heat stress (data not shown). Therefore, the role of HsfAl seems to be unique as master regulator of induced thermotolerance.

\section{Gene-specific silencing of transient HsfA1 expression in mesophyll protoplasts of cosuppression plants}

To investigate the cosuppression phenomenon in more detail, we established a transient gene expression system with tomato mesophyll protoplasts prepared from WT and CS plants grown under aseptic conditions. We selected CS3 plants for these experiments because in this case, the silencing machinery abolished expression of not only the endogenous HsfA1 gene but also of the transgene cassette T1 (Fig. 1C,D). Following our experience with tobacco mesophyll protoplasts (Scharf et al. 1998; Döring et al. 2000), the tomato protoplasts were cotransformed with an Hsf-dependent $\beta$-glucuronidase (GUS) reporter plasmid (phsp17 ${ }^{\star}$ gus) and increasing amounts of plasmids encoding HsfA1, HsfA2, or chimeric proteins containing different portions of both heat stress transcription factors.

The block diagrams in Figure 5A represent the basic structure of HsfA1 (construct 1), HsfA2 (construct 7), and the fusion proteins derived from both (constructs 2-6). In protoplasts from wild-type plants (Fig. 5B, WT), all activator proteins had similar and strong stimulating effects on the expression of GUS. Even $2 \mu$ g of activator plasmid used for transformation of 50,000 protoplasts was sufficient to give a more than 10 -fold increase of the GUS expression compared to the sample transformed with the empty vector only. This sample reflects the endogenous Hsf activity of the protoplasts. These effects correlated with the expression levels of the activator proteins themselves as detected by immunoblot analyses (Fig. 5C, WT).

The results were completely different with protoplasts obtained from the CS3 plants. HsfA1 was not expressed at all, even when protoplasts were transformed with 10 $\mu \mathrm{g}$ (Fig. 5B, CS3) or $20 \mu \mathrm{g}$ (data not shown) of the HsfA1 encoding plasmid. As a consequence, there was no detectable increase of GUS expression above the background. In contrast, samples transformed with HsfA2 expression plasmid (construct 7) gave a marked increase of GUS activity (Fig. 5B, CS3) and a strong HsfA2 signal on the immunoblot (Fig. 5C, CS3). Expression levels and activator function of the chimeric proteins were dependent on the portion of HsfAl in the hybrid construct (Fig. 
Figure 5. Silencing of HsfAl expression in mesophyll protoplasts of CS3 plants. $(A)$ Protoplasts from WT and CS3 plants were transformed with the phsp $17^{\star}$ gus as reporter and increasing amounts of plasmids encoding HsfA1, HsfA2, or fusion proteins harboring different portions of HsfAl (open block diagram) and HsfA2 (shaded block diagram). DBD, DNA binding domain; HR, oligomerization domain, NLS, nuclear localization signal; CTAD, C-terminal activation domain with AHA motifs. $(B)$ Columns represent GUS activity of samples from WT and CS3 protoplasts transformed with 2, 5, or $10 \mu \mathrm{g}$ of activator plasmid. Compared to the results obtained with WT protoplasts, HsfAl expression was completely silenced in CS3 protoplasts. (C) Immunoblot analysis of Hsf expression. For detection, we used a mixture of HsfA1 and HsfA2 specific antisera. The increasing amounts of activator plasmids used for transformation are explained at the bottom.

5A). Expression of the two chimeric Hsfs with major portions of HsfA1 (constructs 2 and 3) was strongly silenced, whereas expression of the two proteins with minor portions of HsfAl was less affected. As expected from the results shown in Figure 3, it was evidently irrelevant for the silencing effect whether the $5^{\prime}$ parts (constructs 2 and 5), the $3^{\prime}$ parts (constructs 3 and 6), or the central part of the fusion construct was derived from the HsfA1 cDNA (no. 4). We conclude from these results that the gene-silencing effect in HsfAl cosuppression plants is very specific, even discriminating between the closely related DNA binding domains of HsfA1 and HsfA2.

\section{Restoration of thermotolerance in mesophyll} protoplasts by transient expression of HsfA2

The experimental system of mesophyll protoplasts from WT and CS plants transformed with the corresponding activator plasmids offered a convenient tool for further investigations on the cellular consequences of the HsfA1 deficiency. Our observations regarding the high heat sensitivity of the CS plants and fruits (Fig. 4) led to the questions of whether this increased sensitivity compared to the WT plants was also detectable at the protoplast level, and whether the thermotolerance of CS3 protoplasts could be restored by transient expression of HsfA2. We used three criteria for thermotolerance: (1) expression of endogenous small Hsps detected by immunoblot analysis, (2) heat protection and renaturation of luciferase as reporter, and (3) formation of the cytoplasmic multichaperone complexes of heat stress granules characteristic of thermotolerant plant cells (Nover et al. 1989; Kirschner et al. 2000).

For the luciferase protection assay (Fig. 6), WT and CS3 protoplasts were cotransformed with a plasmid encoding firefly luciferase $(\mathrm{p} L u c)$ together with empty $\mathrm{pRT}$ vector as control or with pRTHsfA2 (pA2). The four different samples with their transformation and hs treatments are defined by the pictographs and the table in Figure 6A and B. Changes in the luciferase activities in a course of a 30 -min denaturation at $41^{\circ} \mathrm{C}$ and subsequent renaturation for $120 \mathrm{~min}$ at $25^{\circ} \mathrm{C}$, were measured with protoplast samples from WT (Fig. 6C) and CS3 protoplasts (Fig. 6D). In the corresponding immunoblot analyses (Fig. 6E,F), we detected expression levels of luciferase, HsfA1, and HsfA2 as well as Hsp17-CI as indicators of the endogenous chaperone system.

The results with WT protoplasts demonstrated the efficiency of the system. Luciferase was well expressed during the 23-h incubation of the protoplasts after transformation (immunoblots in Fig. 6E). The enzyme was strongly denatured by $30-\mathrm{min}$ incubation at $41^{\circ} \mathrm{C}$ (Fig. $6 \mathrm{C})$, but the extent of denaturation and the following recovery of luciferase were dependent on the pretreatment of the protoplasts prior to the denaturation (Fig. 6A pictographs). Without pretreatment (sample $\mathrm{H}$ ), denaturation was very strong and there was almost no recovery, whereas in thermotolerant protoplasts with hs preinduction (sample P), protection of luciferase by the induced endogenous chaperone system was evident from two effects: the denaturation was less severe, and there was a marked recovery of the activity during the renaturation from $30 \%$ to $50 \%$ of the activity, measured at the onset of the denaturation (100\%). Even better protection could be achieved without hs pretreatment at $40^{\circ} \mathrm{C}$ when protoplasts were transformed with the HsfA2 expression plasmid (sample A2). Evidently, HsfA2 effectively mediated synthesis of major components required for the thermotolerant state, and the luciferase level did not change during the entire procedure (Fig. 6E, immunoblots). To exclude any contribution of de novo synthesis in the recovery period, we added cycloheximide $(10 \mu \mathrm{g} / \mathrm{mL})$ after the denaturation of luciferase at $41^{\circ} \mathrm{C}$. 


\section{A: Temperature treatments}

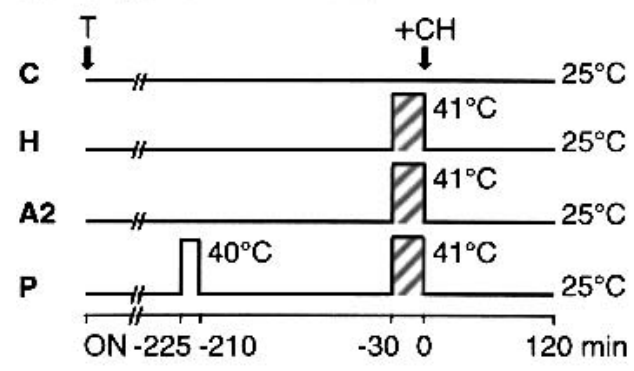

C: WT

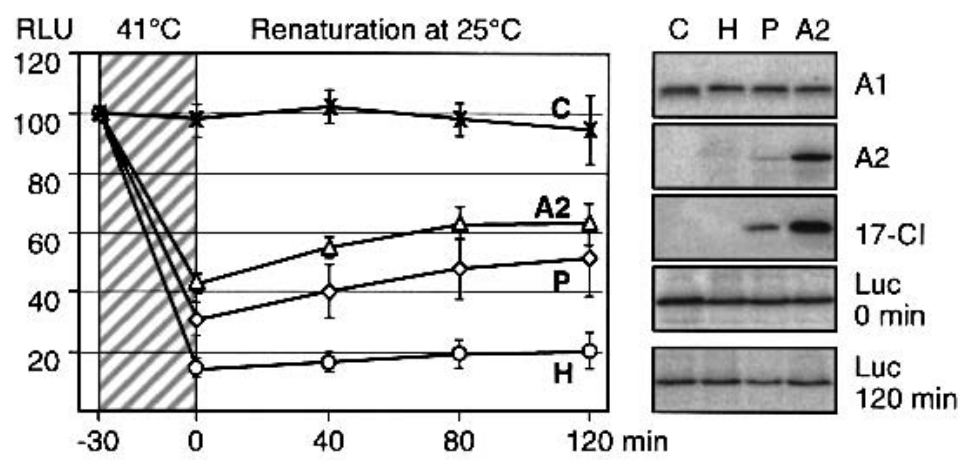

\section{D: CS3}
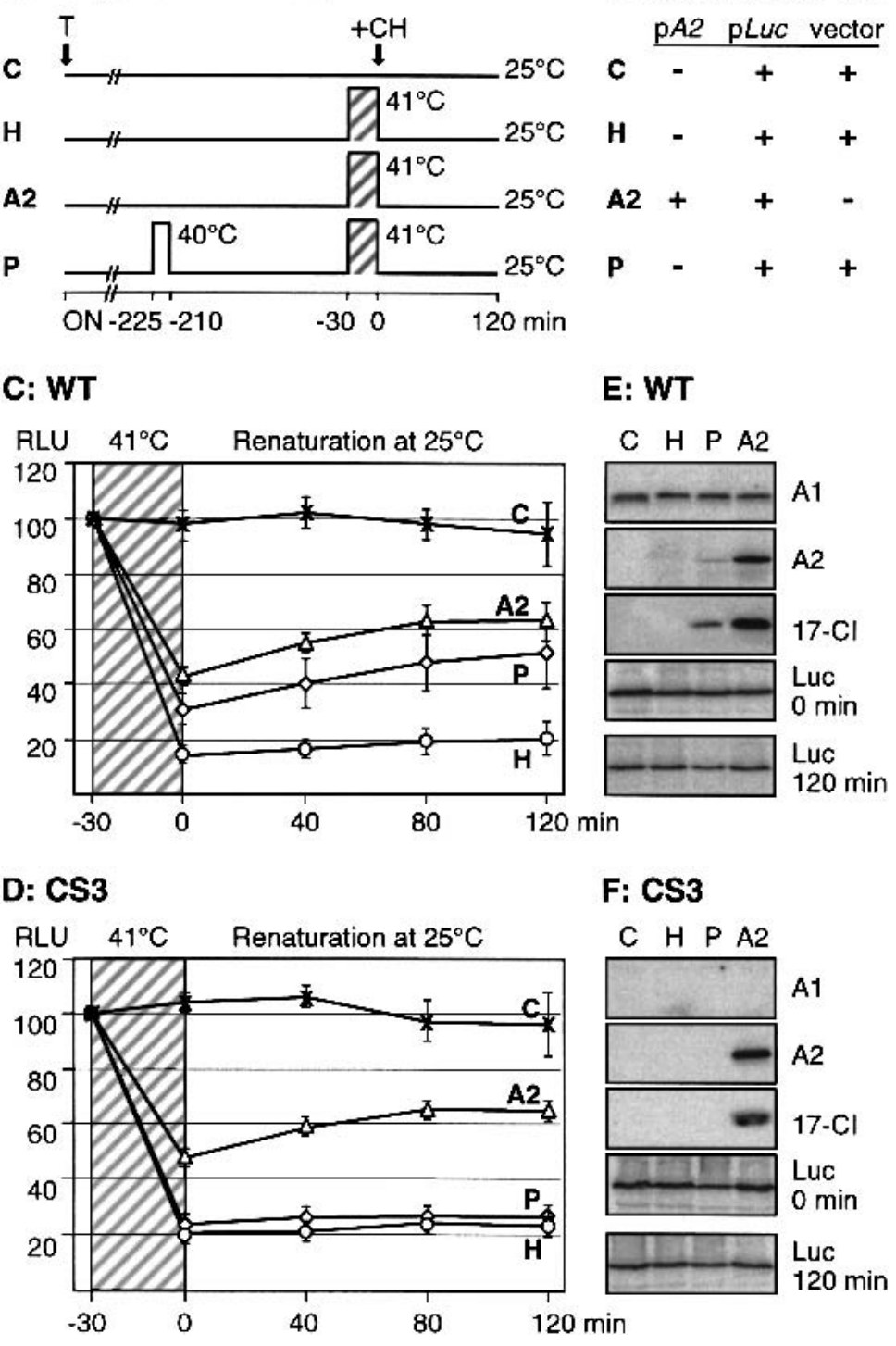

E: WT
B: Transformation with:

Figure 6. Luciferase protection assay in tomato mesophyll protoplasts. $(A, B)$ All four samples of mesophyll protoplasts from WT and CS3 plants were transformed with a luciferase expression plasmid $(\mathrm{p} L u c)$ plus either HsfA2 expression plasmid (pA2, sample A2) or empty vector (samples $\mathrm{C}, \mathrm{P}$ and $\mathrm{H})$. After overnight $(\mathrm{ON})$ incubation at $25^{\circ} \mathrm{C}$, four different hs treatments were applied as indicated by the pictographs in $A$. C: control samples were always kept at $25^{\circ} \mathrm{C}$; P: samples were preconditioned for $20 \mathrm{~min}$ at $40^{\circ} \mathrm{C}$ followed by 3 -h expression of the endogenous chaperone system; samples $\mathrm{H}$ and A2 were not preconditioned. For luciferase denaturation, samples $\mathrm{P}, \mathrm{H}$, and $\mathrm{A} 2$ were treated for $30 \mathrm{~min}$ at $41^{\circ} \mathrm{C}$ and then allowed to recover for $120 \mathrm{~min}$ at $25^{\circ} \mathrm{C}$ for renaturation. Cycloheximide $(\mathrm{CH}, 10 \mu \mathrm{g} / \mathrm{mL})$ was added to all samples prior to the renaturation of luciferase at $25^{\circ} \mathrm{C}$. $(C, D)$ Relative luciferase activities in protoplasts from WT (C) and CS3 (D) plants. Values are based on the luciferase activities given as relative light units (RLU) in \% based on the starting activity at the onset of the denaturation phase $(=100 \%)$. All measurements were done in triplicate. Error bars indicate deviations from the mean value. $(E, F)$ Immunoblot analyses of the corresponding protoplast samples harvested at the end of the renaturation phase. The specific antisera are indicated at the margin.
As expected, the outcome with protoplasts from CS3 plants, although basically comparable, was fundamentally different in one important aspect (Fig. 6D). Because of the lacking HsfA1, there was no protective effect by the preconditioning treatment (sample P). Similar to sample $\mathrm{H}$, luciferase activity in sample $\mathrm{P}$ strongly decreased and did not recover. This defect of the thermotolerance induction was reflected at the protein level by the lack of Hsp17-CI and HsfA2 expression (Fig. 6F, sample P). It could be rescued by transformation with the HsfA2 expression plasmid (sample A2). The extent of luciferase protection in this sample correlated with the expression of HsfA2 and of Hsp17-CI, as an indicator of the endogenous chaperone system (Fig. 6F). These results demonstrate that: (1) transient expression of firefly luciferase in plant protoplasts could be used to monitor the state of the endogenous chaperone system, and (2) in the absence of HsfA1, plasmid-borne expression of HsfA2 could restore the thermotolerant state in CS3 proto- plasts. The same was true for CS3 protoplasts transformed with an expression plasmid encoding tomato HsfA3 (data not shown).

\section{Formation of heat stress granules is correlated with protection of luciferase}

Complexes of heat stress granules (HSGs) ranging up to a few $\mu \mathrm{m}$ in plant cells are usually composed of hundreds of 40-nm particles. Besides Hsp70, they are mainly built of cytosolic small Hsps, classes CI and CII as well as HsfA2, the major hs-inducible Hsf in tomato (Nover et al. 1983; Scharf et al. 1998). What is the state of HSG complexes in protoplasts of CS3 plants? Does the restoration of the thermotolerant state by expression of HsfA2 lead to the assembly of HSG complexes, and is the protection of luciferase associated with its binding to HSG complexes? To explore these questions, we investigated the expression and intracellular localization of 
luciferase and Hsp17-CI in protoplasts from WT and CS3 plants, using indirect immunofluorescence (Fig. 7). Samples were transformed and heat-stressed as described for Figure 6 (see pictograph Fig. 7A). Luciferase was encoded by the pLuc plasmid, whereas Hsp17-CI was used as an indicator for the expression of the endogenous hsinducible genes and typical component of HSGs.

The results can be summarized as follows: After preconditioning treatment of WT protoplasts, Hsp17-CI /detected in the red channel) and luciferase (green channel) were more or less evenly distributed in nucleus and cytoplasm (Fig. 7B, WT sample P). The web-like structure of the immunofluorescence is due to the cytoplasmic strands interspersed between the nonstained chloroplasts. During the following $30-\mathrm{min}$ hs at $41^{\circ} \mathrm{C}, \mathrm{Hsp} 17-$ $\mathrm{CI}$ and luciferase became part of the same cytoplasmic aggregates representing HSG complexes. This aggregation tendency became even more prominent in samples maintained for $120 \mathrm{~min}$ at $41^{\circ} \mathrm{C}$. In protoplasts from CS3 plants, Hsp17-CI synthesis and HSG assembly could not be detected (Fig. 7C) unless protoplasts were transformed with the HsfA2 encoding plasmid (Fig. 7D). In the recovery (R, Fig. 7D), structural binding of luciferase was slowly reversed, corresponding to its reactivation in the enzyme assay (Fig. 6D). In CS3 protoplasts expressing HsfA2, all details of reversible association of luciferase with Hsp17-CI in HSG complexes were similar or indistinguishable from those found in WT protoplasts (Fig. 7B vs. 7D, panels R).
The immunofluorescence pictures cannot answer the question of whether all proteins necessary for assembly of the HSG complexes with the typical 40-nm particles are formed in nonheat-stressed protoplasts transformed with HsfA2 expression plasmid only. From previous results with coexpression of Hsp17-CI and Hsp17-CII in tobacco protoplasts, we concluded that, in addition to the small Hsps, other components are required to give the characteristic ultrastructure of the HSG complexes (Kirschner et al. 2000). To clarify this point, we investigated the ultrastructure of tomato protoplasts (Fig. 8). After hs treatment of WT protoplasts, HSG complexes were easily detected irrespective of the transformation with empty vector or with pRTHsfA2 (see encircled parts in Fig. 8A and B, WT). However, in CS protoplasts, formation of HSG complexes could be seen only after transformation with pRTHsfA2 (Fig. 8B, pA2). These results emphasized once more the functional equivalence of HsfA1 and HsfA2. The failure of the latter to substitute for the former in the CS plants merely results from its lacking expression, which is HsfAl-dependent.

\section{Discussion}

\section{Molecular basis of HsfA1 gene silencing}

The transgenic lines analyzed in this study were all progenies of a single $T_{0}$ tomato plant selected on the basis of its kanamycin resistance. The primary transformation event in this case led to the integration of three trans-
Figure 7. Intracellular localization of luciferase and Hsp17-CI in tomato protoplasts by immunofluorescence analysis. Details of the transformation and hs regime are indicated in the pictograph at the top $(A)$. Protoplasts of WT and CS3 plants were transformed with $\mathrm{pLuc}$ and empty pRT vector $(B, C)$. In addition, samples of CS3 protoplasts were transformed with luciferase and HsfA2 expression plasmids $(D)$. The processing of protoplasts for immunofluorescence was as described before (Scharf et al. 1998; Kirschner et al. 2000). Luciferase was detected in the green and Hsp17-CI in the red channel. Arrowheads in sample B, row H2 mark cytoplasmic HSG complexes detected by both antibodies.
A
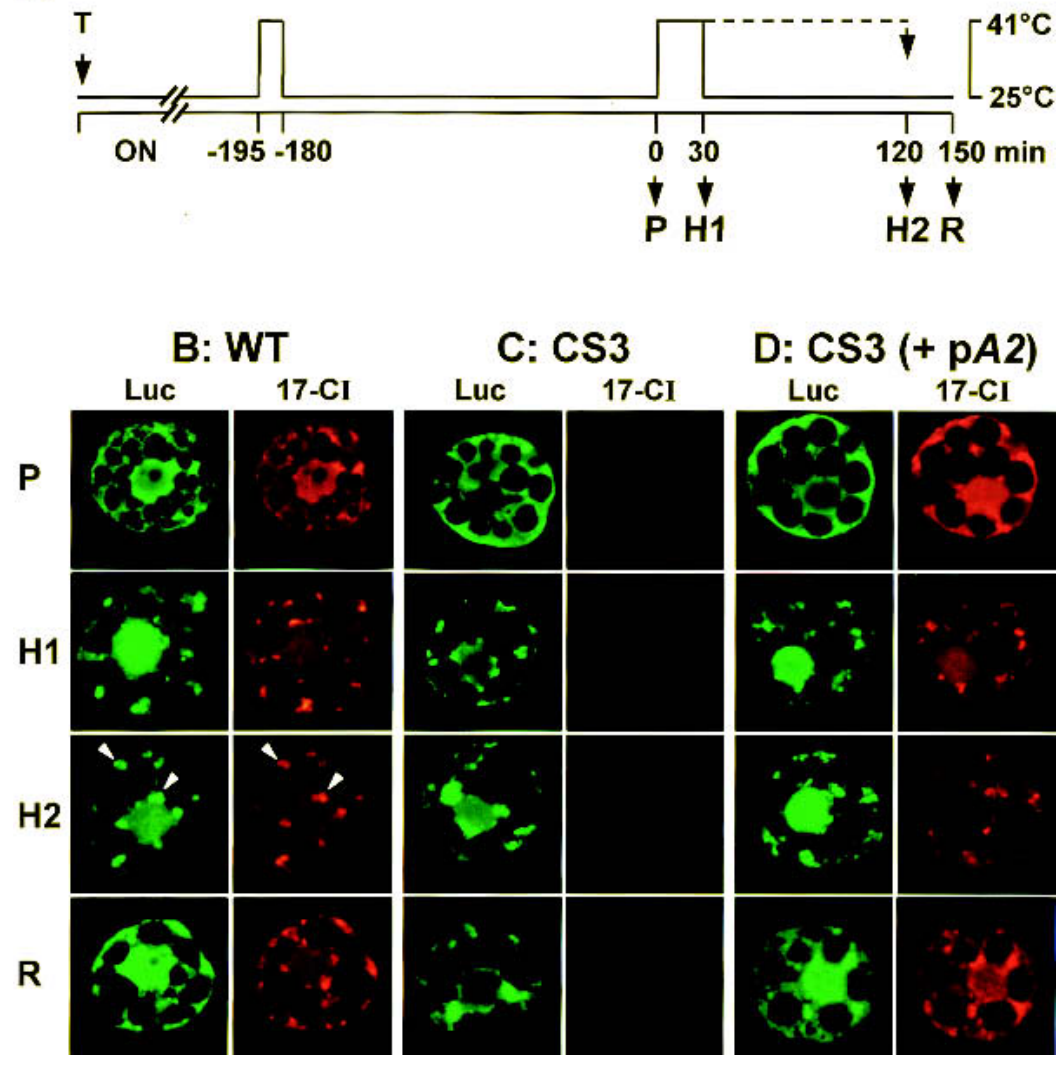
Tomato HsfA1 as master regulator of thermotolerance

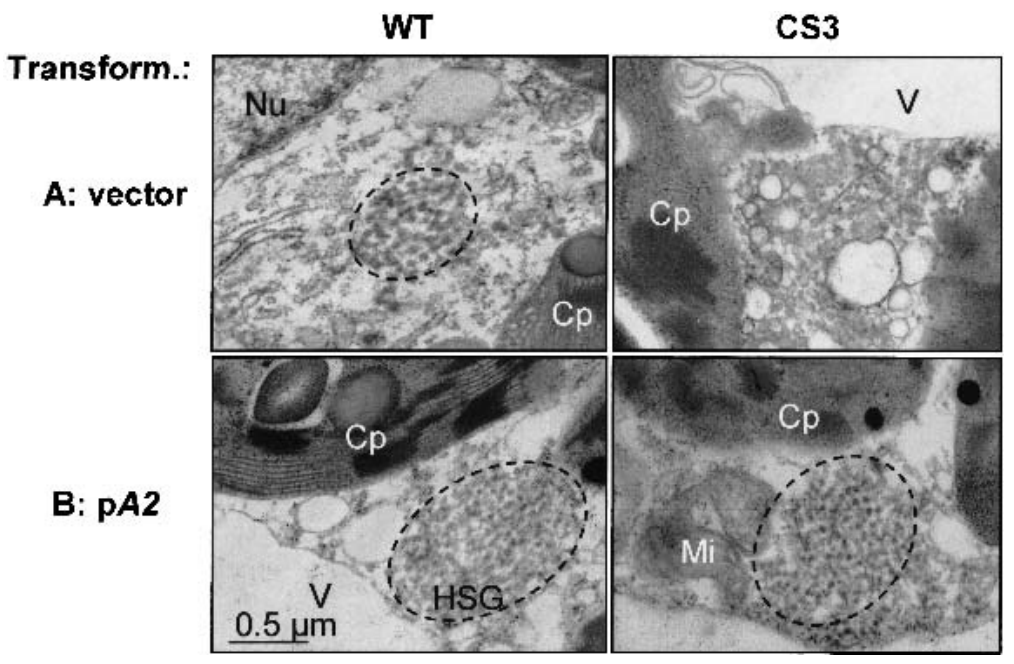

Figure 8. Restoration of HSG complexes in CS protoplasts by transformation with pRTHsfA2. Protoplasts were transformed with empty vector or with pRTHsfA2 (pA2). After $16 \mathrm{~h}$ of cultivation they were preconditioned, and after another 3 -h cultivation at $25^{\circ} \mathrm{C}$ they were subjected to a second hs for $2 \mathrm{~h}$ at $40^{\circ} \mathrm{C}$ (see pictograph Fig. 7A, sample H2). Processing of protoplasts for electron microscopy was described by Kirschner et al. (2000). Cp, chloroplast; Mi, mitochondria; $\mathrm{Nu}$, nucleus; $\mathrm{V}$ vacuole. Bar represents $0.5 \mu \mathrm{m}$. HSG complexes are circled. gene cassettes. One of them is strongly expressed and, if present alone, gives rise to HsfAl overexpression plants. The other two cassettes are the result of integration of a tandem inverted repeat causing the cosuppression effect, which is dominant over the overexpression effect. Hence, in the CS3 plants with all three transgene cassettes, HsfA1 expression is strongly reduced, almost to the level of CS2 plants (Fig. 1). The efficiency of the cosuppression machinery in CS3 plants is strong enough to silence expression of HsfAl in mesophyll protoplasts even when transformed with very high amounts of the HsfAl expression plasmids (Fig. 5).

Phenomena of gene silencing are widespread in plants and other eukaryotes. Recent findings indicate that peculiarities of transgene arrangements, most frequently observed with integration of direct or inverted repeats, lead to the generation of aberrant RNA and formation of dsRNA. These RNAs can be processed to siRNAs responsible for the ATP-dependent, sequence-specific degradation of mRNA (Wolters and Visser 2000; Ambros 2001; Elbashir et al. 2001; Lipardi et al. 2001; Sharp 2001). The detection of small RNAs of about 21-nt by both sense and antisense riboprobes of HSfA1 in CS2 and CS3 tomato and the lack of such siRNAs in WT and OE plants (Fig. 3) strongly support their decisive role for the cosuppression phenomenon. Due to the dominant epigenetic components, the extent of gene silencing in plants is dynamic and may be influenced by the developmental state and growth conditions (Meins 2000). This provides a possible explanation for the differences in the strength of the cosuppression effects in leaves versus pericarp of CS plants (Fig. 1).

\section{The binding of luciferase to the HSG complexes}

Assembly of HSG complexes is characteristic for heatstressed plant cells. These cytoplasmic complexes, comprised of electron-dense 40-nm particles, are most prominent in cells with high capacity for Hsp synthesis, for example meristematic cells, rapidly growing cell suspension cultures, or mesophyll protoplasts (Nover et al. 1983, 1989; Neumann et al. 1984). Although the domi- nant components are the cytosolic sHsps, additional hsinducible proteins, such as Hsp70 and HsfA2, are also involved in the assembly of these characteristic structures (Neumann et al. 1987; Scharf et al. 1998; Kirschner et al. 2000).

As expected from the lack of essential components, formation of HSG complexes was not observed in heatstressed protoplasts derived from the CS3 plants unless transformed with HsfA2 expression plasmids (Figs. 7, 8). Despite the lack of HsfA1, all components necessary for HSG assembly were evidently synthesized in the presence of HsfA2. Under these conditions, protection of luciferase from irreversible heat damage was restored, and this was associated with the formation of the HSG complexes. By indirect immunofluorescence, we found a major part of luciferase bound to the HSG complexes (Fig. 7). Hence, the multichaperone complexes in the cytoplasm may indeed form a type of matrix for stabilization of denatured proteins, as predicted earlier for small Hsps in general (Kimpel and Key 1985). Renaturation requires cooperation with ATP-dependent chaperone systems, for example the Hsp70, Hsp90, and/or Hsp104 systems (Forreiter et al. 1997; Lee et al. 1997; Lee and Vierling 2000). It must be noted that the capability of sHsps to serve as reservoirs for intermediates of protein folding or denatured proteins created by hs is a general property of these proteins and does not necessarily require assembly of HSG complexes. It was also observed with individual members of the sHsp family, including those from yeast and animals, and it is associated with profound structural rearrangements of the regular oligomers to irregular high molecular weight aggregates incorporating the substrate proteins (Ehrnsperger et al. 1997, 1999; Löw et al. 2000).

The role of tomato HsfA1 as the master regulator and the complexity of the Hsf family

Transgenic Arabidopsis or carrot with altered expression of hs-inducible genes have been reported. Two different experimental approaches were selected: (1) Expression of fusion proteins of AtHsfAla (Hsfl) with GUS in Arabidopsis (Lee et al. 1995) caused constitutive expression of 
sHsps and increased thermotolerance comparable to the phenotype observed with our tomato OE lines. (2) Transformation of Arabidopsis with antisense cassettes of Hsp70 (Lee and Schöffl 1996) or Hsp104 (Queitsch et al. 2000) as well as transformation of carrot with Hsp17 antisense cassettes (Malik et al. 1999) led to more or less pronounced reductions of the chaperone expression levels. In all cases, the observed effects on thermotolerance support the view that a complex network of interacting hs-inducible proteins is necessary and that the lack or diminished expression of any one of the major chaperones affects the development of thermotolerance. This is also true for mutants of Arabidopsis with defects of Hsp104 expression (Hong and Vierling 2000, 2001). To date, screening for thermosensitive mutants of Arabidopsis (Severin et al. 1995; Hong and Vierling 2000) for the identification of a regulatory gene which might encode a master regulator of the hs response have been unsuccessful.

Considering this situation, the effects of posttranscriptional silencing of the HsfA1 gene in the CS plants of tomato were totally unexpected. The strongly reduced or undetectable expression of HsfAl resulted in a general lack of induced Hsp synthesis and thermotolerance associated with severe defects in growth and development, even under mild hs conditions, whereas the wild-type plants and fruits were not visibly affected (Figs. 1, 4). CS plants were completely normal under standard greenhouse conditions. In this context, it is worth recalling that transgenic tomato plants with strongly reduced or absent expression of HsfA2 or HsfB1 had no comparable defects in the hs response (data not shown). Evidently, the presence of HsfAl is sufficient to ensure Hsp synthesis. The two hs-inducible Hsfs A2 and B1 certainly influence details of the gene expression, but they are probably not indispensable for the thermotolerant state.

\section{Functional diversification of tomato Hsfs}

The multiplicity of plant Hsfs leads to the question of redundancy versus functional diversification of the individual members. Based on our results with the CS plants, we must conclude that the deficiency of HsfA1 expression cannot be complemented by any of the other closely related tomato Hsfs. Although our knowledge is still very limited, the functional analysis of the four tomato Hsfs cloned so far supports the concept of a marked diversification (Scharf et al. 1990, 1993, 1998; Treuter et al. 1993; Boscheinen et al. 1997; Lyck et al. 1997; Bharti et al. 2000; Döring et al. 2000; Heerklotz et al. 2001). Evidently, each of these Hsfs has its own role in a complex network determined by the pattern of expression, intracellular localization, oligomerization behavior, activator function, and interaction of Hsfs with other proteins (for review, see Nover et al. 2001). Tomato HsfB1 is particularly remarkable because it has no activator function of its own but acts as a strong synergistic coactivator if combined with other class A Hsfs (K. Bharti and P. Döring unpubl.).

The dominant phenotype of the HsfAl cosuppression plants adds another example to this diversification. Part of the explanation for the unique role of HsfAl as master regulator is based on the observation that in the cosuppression plants, expression of the two hs-inducible Hsfs A2 and B1 was strongly reduced or lacking, together with the expression of other hs-inducible proteins. It is tempting to speculate about a simple sequential model of hsinduced gene expression involving HsfA2 and HsfB1 as HsfA1-dependent enhancer or modifier of Hsp synthesis. In support of such a model, HsfA2 was characterized as a potent activator of reporter gene expression in general (Treuter et al. 1993; Scharf et al. 1998; Döring et al. 2000; Heerklotz et al. 2001). Moreover, in the test situation of protoplasts from CS plants, the defect of the hs response could be repaired by plasmid-borne HsfA2 expression. The efficiency of HsfA2 in these restoration assays (Figs. 6-8) was not anticipated. Usually, the strong nuclear export signal at the $\mathrm{C}$ terminus of HsfA2 precludes a significant retention in the nucleus unless it exists in heterooligomers with HsfA1 (Scharf et al. 1998; Heerklotz et al. 2001). We assume that other class A Hsfs of tomato may fulfill this function. However, due to the relatively low expression levels, these unidentified coactivators are not able to replace HsfA1 to induce thermotolerance. Unfortunately, this interesting aspect can only be clarified when specific antisera become available to investigate the expression of other members of the tomato Hsf family in more detail. Although the existence of ESTs for more than 17 Hsfs in tomato (Nover et al. 2001) and our preliminary RT-PCR analyses (data not shown) demonstrate that the genes are transcribed under nonstress conditions, it does not necessarily indicate that the corresponding proteins accumulate to levels comparable to those detected for HsfA1, HsfA2, and HsfB1 (Bharti et al. 2000). This is supported by the results from the electrophoretic mobility shift assay (Fig. 2), with no detectable signal in the samples from CS2 and CS3 plants.

Although HsfA2 is functionally equivalent to HsfA1 in the experimental situation of mesophyll protoplasts derived from CS plants (Figs. 6-8), it cannot substitute for HsfA1 as master regulator, because its expression in whole plants is dependent on HsfAl (Fig. 1). These mesophyll protoplasts of CS plants represent a valuable test system for our understanding of the functional diversification of other members of the Hsf family. Effects of different Hsfs and Hsf combinations can be easily investigated not only with appropriate reporter constructs but above all in the complex cellular response of Hsf-induced thermotolerance, as exemplified by the results shown in Figures 6-8.

\section{Materials and methods}

\section{General materials and methods}

Rabbit antisera against tomato HsfA1, HsfA2, HsfB1, Hsp17 class CI, and Hsp70 were described previously (Lyck et al. 1997; Kirschner et al. 2000). Luciferase antiserum was obtained from Sigma. The Hsp104 antiserum was kindly provided by Anil Grover (University South Campus, New Delhi, India). Secondary antibodies against rabbit immunoglobulins conjugated with horseradish peroxidase or fluorescent dyes CY2 or CY3 were obtained from Sigma and Dianova, respectively. 
Standard procedures were used for cloning (Ausubel et al. 1993; Sambrook and Russell 2001). Plant expression vectors are derivatives of pRT101 (Töpfer et al. 1988). For convenient deletions or combinations of functional parts of HsfA1 and HsfA2, we generated unique SalI sites in different regions of the cDNAs introduced by site-directed mutagenesis (Treuter et al. 1993; Döring et al. 2000). The principle modular structures of the chimeric proteins of Hsfs $\mathrm{A} 1$ and $\mathrm{A} 2$ are given in the block diagrams in Figure 5A.

For indirect immunofluorescence of protoplasts, we followed the procedures described by Scharf et al. (1998) and Heerklotz et al. (2001). Fixation of protoplasts was done with $3.7 \%$ paraformaldehyde in microtubule stabilizing buffer (100 mM PIPES buffer at $\mathrm{pH}$ 6.8, 2 mM EGTA, $1 \mathrm{mM} \mathrm{MgSO}$ ). Preparation of protoplasts for electron microscopy was as described by Kirschner et al. (2000).

\section{Generation and selection of transgenic plants}

For transformation of tomato (Lycopersicon esculentum cv. Moneymaker), the Agrobacterium tumefaciens strain GV3101(pMP90) was used as described (Koncz and Schell 1986). The binary vector pGPTV-KAN (Becker et al. 1992) was modified by removing the $\beta$-glucuronidase (uid A) gene and insertion of the HindIII fragment containing the HsfA1 cDNA expression cassette from the corresponding $\mathrm{pRT}$ vector (Scharf et al. 1990). In the construct used for transformation, the expression cassette of $H s f A 1$ with the cauliflower mosaic virus (CaMV) 35S promoter points towards the right T-DNA border $(\mathrm{RB})$ and therefore opposite to the direction of the NPTII selection marker gene, whose expression is under the control of the NOS promoter (Fig. 1A).

Leaf disc transformation and plant regeneration were done as described (Knapp et al. 1994). Calli were generated on $\mathrm{Mu}$ rashige-Skoog nutrient medium (Duchefa) containing $100 \mu \mathrm{g} /$ $\mathrm{mL}$ kanamycin and $500 \mu \mathrm{g} / \mathrm{mL}$ carbenicillin. For shoot induction, $2 \mu \mathrm{g} / \mathrm{mL}$ zeatin (Duchefa) was added. After root formation, regenerated $\mathrm{T}_{0}$ plants were transferred to soil and further grown in the greenhouse under 16 -h light $/ 8$-h dark at $24^{\circ} \mathrm{C}$ and $18^{\circ} \mathrm{C}$, respectively. Segregation of the $\mathrm{T}_{0}$ lines was followed for at least the next three generations $\left(\mathrm{F}_{1}\right.$ to $\left.\mathrm{F}_{3}\right)$ by kanamycin resistance tests and Southern analysis.

The kanamycin resistance test was performed about 2 wk after germination by spraying plants on 3 consecutive $d$ with a solution containing $0.5 \mathrm{mg} / \mathrm{mL}$ kanamycin sulfate and $0.05 \%$ sapogenate as detergent (Clarion). Four days later, the young leaves of sensitive plants turn yellow, whereas leaves of transgenic plants are resistant to the antibiotic and remain green.

\section{Southern analysis}

Genomic DNA was extracted by the CTAB buffer method as described by Ausubel et al. (1993). Ten micrograms of the DNA per sample was digested overnight, separated on $1.5 \%$ agarose gels and pressure blotted (Stratagene) to positively charged nylon membrane (Roche). Southern hybridization was performed following the manufacturer's protocol (Roche). Primers used for PCR generation of the DIG-labeled probes were the following: $\operatorname{PrHsfA1}$ F, 5'-GCACCTGCTTAAAAGTATAAGAAGTCGG-3'; $\operatorname{Pr} H s f A 1$ R, 5' -CCTGAAGAGTGACTCCTGAAACAC-3'; $\operatorname{Pr} N$ ptII F, 5'-CCTGTCATCTCACCTTGCTCCTGCC-3'; PrNptII R, 5'-CGATACCGTAAAGCACGAGGAAGC-3'.

\section{Northern analysis}

Total RNA from leaves and fruit pericarp was prepared with the guanidinium thiocyanate procedure (Ausubel et al. 1993). Fifteen micrograms of total RNA was separated on denaturing
$1.2 \%$ agarose gels and pressure blotted (Stratagene) to positively charged nylon membrane (Amersham Pharmacia). Hybridization using DIG-labeled probes was performed at $55^{\circ} \mathrm{C}$ overnight following the manufacturer's protocol (Roche).

The primers used to generate DIG-labeled probes were: $\operatorname{Pr} H s f A 2$ F, 5'-GGATCCTGACAGATGGGAATTTGCG-3'; PrHsfA2 R, 5'-CCATTTGCTGTCACAACAGAATCCG-3'; PrHsfB1 F, 5'GGATGACATAGGTTCAAGTTCTACC- ${ }^{\prime}$; PrHsfB1 R, $5^{\prime}$-GCG AAGACATTTTCATCCAAGGACC-3'; PrHsp70 F, 5' -GGTCCT GACATGGCTGGTGG-3'; PrHsp70 R, 5'-GTACATAAGAAGA TAAGTTTGGC-3'; PrHsp17-CI F, 5' -TATTGAAATCTCTGGT TAAAACTTCATT TGT-3'; PrHsp17-CI R, 5'-GCCCGGGGGA TCTCAAAAGGACTAG TATTTCATATT- $3^{\prime}$.

The DIG-labeled probe for the Northern analysis of HsfA1 was the same as that used for the Southern analysis.

\section{Electrophoretic mobility shift assay}

Details of the electrophoretic mobility shift assays including the HSE3 oligonucleotides were described previously (Scharf et al. 1990; Boscheinen et al. 1997). For preparation of nuclei from leaf tissue, we used the procedure of Jensen et al. (1988). Proteins from the nuclear preparations were extracted with NEB500 buffer ( $25 \mathrm{mM}$ HEPES, $500 \mathrm{mM} \mathrm{NaCl}, 5 \mathrm{mM} \mathrm{MgCl}_{2}, 1$ mM EDTA, $10 \mathrm{mM} \mathrm{NaF}, 0.2 \%$ NP-40, and a cocktail of protease inhibitors from Roche). One nanogram of ${ }^{32} \mathrm{P}$-labeled HSE3 oligonucleotide were incubated for $20 \mathrm{~min}$ at $25^{\circ} \mathrm{C}$ with $5 \mu \mathrm{g}$ of nuclear protein extracts; samples were separated on $5 \%$ native polyacrylamide gels, and the position of radioactivity was detected by 18 -h exposure to $\mathrm{x}$-ray films. The two oligonucleotides used for competition were 5'-GCCAGAAGCTTCTAGAAA GC-3' (wild-type HSE3c) and 5'-GCCATAAGCTTG $\underline{\text { TACAAAA }}$ GC-3' (mutant HSE3c, changed nucleotides underlined).

Heat stress and protein analysis of transgenic plants and fruits

Four- to six-week-old plants were heat stressed for $1 \mathrm{~h}$ at $45^{\circ} \mathrm{C}$ in a climate chamber, followed by 2 -h incubation at $25^{\circ} \mathrm{C}$. Upper 2-3 young leaves were collected and stored at $-80^{\circ} \mathrm{C}$. Mature green fruits were heat stressed at $42^{\circ} \mathrm{C}$ for $4 \mathrm{~h}$ in the climate chamber. Fruit pericarp was separated and stored at $-80^{\circ} \mathrm{C}$. For protein extraction, the tissues were ground in liquid $\mathrm{N}_{2}$. Next, 100-200 mg of the frozen powder was transferred into Eppendorf tubes and sonicated in two volumes of NEB500 buffer. One volume of protein extract containing about $30 \mu \mathrm{g}$ of protein was heated with an equal volume of $2 \times$ SDS sample buffer and then separated on $12 \%$ SDS-polyacrylamide gels. Because of the lower protein content, the NEB500 extracts of fruit pericarp were precipitated with 4 volumes of acetone, and proteins were dissolved in $1 \times$ SDS sample buffer. For the immunoblot analysis, proteins were transferred to $45 \mu \mathrm{m}$ nitrocellulose membrane (Schleicher and Schuell) and further processed for chemiluminescence detection following the manufacturer's protocol (NEN).

\section{Isolation of small interfering RNA (siRNA) and hybridization}

For the isolation of soluble RNA, large RNAs were precipitated by LiCl. The supernatant was overlaid with 3 vol of ethanol and large genomic DNA was spooled out. After precipitation overnight at $-20^{\circ} \mathrm{C}$, the pellet of small RNA was dissolved in $200 \mu \mathrm{L}$ water, residual DNA was removed by treatment with DNaseI (Roche Diagnostics), followed by Proteinase K and phenol-chloroform treatment. After precipitation with 3 vol of ethanol, small RNAs were redissolved in $200 \mu \mathrm{L}$ water. 
Electrophoresis of siRNA on $15 \%$ polyacrylamide $7 \mathrm{M}$ urea gels, transfer on positively charged nylon membrane (Amersham Pharmacia Biotech), and hybridization were as described by Hamilton and Baulcombe (1999). The transfer was done by a semidry method at constant current $\left(1 \mathrm{~mA} / \mathrm{cm}^{2}\right.$ of the membrane) for $2 \mathrm{~h}$ using $1 \times$ TBE buffer similar to that used during electrophoresis. For hybridization, $\left[{ }^{32} \mathrm{P}\right] \mathrm{UTP}$-labeled riboprobes were generated by in vitro transcription (Promega) of an HsfA1 cassette flanked by a $\mathrm{T} 7$ promoter (sense transcript) and $\mathrm{T} 3$ promoter (antisense transcript). The riboprobes were hydrolyzed at $60^{\circ} \mathrm{C}$ for 90 min using sodium carbonate buffer $(\mathrm{pH}$ $10.2)$ to an average length of 50-100 nucleotides. For size marker and control of strand-specific hybridization, we used synthetic 23-nt sense and antisense ribooligonucleotides corresponding to the $\mathrm{N}$ terminus of the HsfA1 cassette (BioSpring). Hybridization was done at $37^{\circ} \mathrm{C}$ overnight.

\section{Reporter constructs and assays with tomato protoplasts}

The use of tomato mesophyll protoplasts for polyethylene glycol (PEG)-mediated transformation and transient gene expression is based on the published vectors and procedures for tobacco protoplasts (Treuter et al. 1993; Scharf et al. 1998). The only major difference concerns the protoplasting procedure, which was done in K3M instead of K3S solution; that is, $0.4 \mathrm{M}$ sucrose was replaced by $0.4 \mathrm{M}$ mannitol. After protoplasting overnight, 1 vol of K3S (with a twofold concentration of sucrose) was added, and protoplasts were enriched by centrifugation at $500 \mathrm{rpm}$.

For the GUS reporter assay, we used the phsp $17^{\star}$ gus vector (Treuter et al. 1993; Heerklotz et al. 2001). For construction of the $\mathrm{p} L u c$ vector for the luciferase assay, we replaced the GFP cassette in pCRGFP vector (Reichel et al. 1996) by an NcoI/XbaI fragment of the Promega pGL3 basic vector encoding firefly luciferase. The plant expression vector is a modified $\mathrm{pRT}$ vector containing a duplicated CaMV35S enhancer and a tobacco etch virus translational enhancer preceding the ATG start codon (Carrington et al. 1991).

After PEG-mediated transformation with the indicated expression plasmids, protoplasts were incubated for $15 \mathrm{~h}$ at $25^{\circ} \mathrm{C}$ under dim light. The measurement of the $\beta$-glucuronidase (GUS) reporter activity is based on the method described by Jefferson (1987) with a few modifications (Döring et al. 2000). For the luciferase reporter assay, denaturation was performed by heating protoplasts in a water bath for $30 \mathrm{~min}$ at $41^{\circ} \mathrm{C}$. Cycloheximide was added immediately after the denaturation (final concentration $10 \mu \mathrm{g} / \mathrm{mL}$ ), and cells were allowed to recover for $2 \mathrm{~h}$ at $25^{\circ} \mathrm{C}$. Luciferase activity was determined directly before and after the denaturation and at 20-min intervals during the recovery. At each timepoint, three parallel samples of the protoplast suspension containing 2500 protoplasts were transferred to a 96-well microtiter plate. The assay was performed using a Mikrolumat LB 96P luminometer (EG\&G Berthold). Following the injection of $100 \mu \mathrm{L}$ of luciferase assay reagent $(25 \mathrm{mM}$ glycylglycine, $15 \mathrm{mM} \mathrm{K}$-phosphate at $\mathrm{pH} 7.8,15 \mathrm{mM} \mathrm{MgCl}_{2}, 4$ mM EGTA, 1 mM DTT, 1 mM ATP, $40 \mu M$ luciferin), light emission was measured for $20 \mathrm{sec}$ (Forreiter et. al. 1997). Values were normalized to the activity measured before the denaturation at $41^{\circ} \mathrm{C}$ (equals $100 \%$ ). Experiments were repeated at least three times.

\section{Acknowledgments}

We thank Gisela Englich, Daniela Bublak, and Christel Rülke for excellent technical assistance, as well as Holger Schranz and Gerald Kircher as members of the greenhouse team. We thank Kapil Bharti, Markus Fauth, and Dirk Zielinski for many helpful discussions during the preparation of the manuscript. This work was supported by grants of the Bundesministerium für Bildung and Forschung to K.D.S. and of the Deutsche Forschungsgemeinschaft to L.N. as well as to S.K.M. as fellow of the Graduiertenkolleg.

The publication costs of this article were defrayed in part by payment of page charges. This article must therefore be hereby marked "advertisement" in accordance with 18 USC section 1734 solely to indicate this fact.

\section{References}

Agashe, V.R. and Hartl, F.U. 2000. Roles of molecular chaperones in cytoplasmic protein folding. Semin. Cell Dev. Biol. 11: $15-25$.

Ambros, V. 2001. microRNAs: Tiny regulators with great potential. Cell 107: 823-826.

Ausubel, F.M., Brent, R., Kingston, R.E., Moore, D.D., Seidman, J.G., Smith, J.A., and Struhl, K. 1993. Current protocols in molecular biology. John Wiley and Sons, New York, NY.

Becker, D., Kemper, E., Schele, J., and Masterson, R. 1992. Vectors with selectable markers located proximal to the left T-DNA border. Plant Mol. Biol. 20: 1195-1197.

Bharti, K., Schmidt, E., Lyck, R., Bublak, D., and Scharf, K.-D. 2000. Isolation and characterization of HsfA3, a new heat stress transcription factor of Lycopersicon peruvianum. Plant J. 22: 355-365.

Boscheinen, O., Lyck, R., Queitsch, C., Treuter, E., Zimarino, V., and Scharf, K.-D. 1997. Heat stress transcription factors from tomato can functionally replace HSF1 in the yeast Saccharomyces cerevisiae. Mol. Gen. Genet. 255: 322-331.

Carrington, J.C., Freed, D.D., and Leinicke, A.J. 1991. Bipartite signal sequence mediates nuclear translocation of the plant potyviral NIa protein. Plant Cell 3: 953-962.

Döring, P., Treuter, E., Kistner, C., Lyck, R., Chen, A., and Nover, L. 2000. Role of AHA motifs for the activator function of tomato heat stress transcription factors HsfAl and HsfA2. Plant Cell 12: 265-278.

Ehrnsperger, M., Graber, S., Gaestel, M., and Buchner, J. 1997. Binding of non-native protein to Hsp25 during heat shock creates a reservoir of folding intermediates for reactivation. EMBO J. 16: 221-229.

Ehrnsperger, M., Lilie, H., Gaestel, M., and Buchner, J. 1999. The dynamics of Hsp25 quarternary structure. J. Biol. Chem. 274: 14867-14874.

Elbashir, S., Lendeckel, W., and Tuschl, T. 2001. RNA interference is mediated by 21 - and 22-nucleotide RNAs. Genes \& Dev. 15: 188-200.

Ellis, R.J. 2000. Chaperone substrates inside the cell. Trends Biochem. Sci. 25: 210-212.

Forreiter, C., Kirschner, M., and Nover, L. 1997. Stable transformation of an Arabidopsis cell suspension culture with firefly luciferase providing a cellular system for analysis of chaperone activity in vivo. Plant Cell 9: 2171-2181.

Hamilton, A.J. and Baulcombe, D.C. 1999. A species of small antisense RNA in posttranscriptional gene silencing in plants. Science 286: 950-952.

Heerklotz, D., Döring, P., Bonzelius, F., Winkelhaus, S., and Nover, L. 2001. The balance of nuclear import and export determines the intracellular distribution of tomato heat stress transcription factor HsfA2. Mol. Cell. Biol. 21: 1759-1768.

Hong, S.W. and Vierling, E. 2000. Mutants of Arabidopsis thaliana defective in the acquisition of tolerance to high temperature stress. Proc. Nat1. Acad. Sci. 97: 4392-4397. . 2001. Hsp101 is necessary for heat tolerance but dis- 
pensable for development and germination in the absence of stress. Plant J. 27: 25-35.

Jefferson, R.A. 1987. Assaying chimeric genes in plants: The GUS gene fusion system. Plant Mol. Biol. Rep. 5: 387-405.

Jensen, E.O., Marcker, K.A., Schell, J., and de Bruijn, F.J. 1988. Interaction of a nodule specific, trans-acting factor with distinct DNA elements in the soybean leghaemoglobin $1 b c_{3} 5^{\prime}$ upstream region. EMBO J. 7: 1265-1271.

Jolly, C. and Morimoto, R.I. 2000. Role of the heat shock response and molecular chaperones in oncogenesis and cell death. J. Nat1. Cancer Inst. 92: 1564-1572.

Kimpel, J.A. and Key, J. 1985. Heat shock in plants. Trends Biochem. Sci. 10: 353-357.

Kirschner, M., Winkelhaus, S., Thierfelder, J., and Nover, L. 2000. Transient expression and heat stress induced aggregation of endogenous and heterologous small heat stress proteins in tobacco protoplasts. Plant J. 24: 397-412.

Knapp, S., Larondelle, Y., Roßberg, M., Furtek, D., and Theres, K. 1994. Transgenic tomato lines containing Ds elements at defined genomic positions as tools for targeted transposon tagging. Mol. Gen. Genet. 243: 666-673.

Koncz, C. and Schell, J. 1986. The promoter of $\mathrm{T}_{\mathrm{L}}$-DNA gene controls the tissue-specific expression of chimaeric genes carried by a novel type of Agrobacterium binary vector. Mol. Gen. Genet. 204: 383-396.

Lee, G.J. and Vierling, E. 2000. A small heat shock protein cooperates with heat shock protein 70 systems to reactivate a heat-denatured protein. Plant Physiol. 122: 189-198.

Lee, G.J., Roseman, A.M., Saibil, H.R., and Vierling, E. 1997. A small heat shock protein stably binds heat-denatured model substrates and can maintain a substrate in a folding-competent state. EMBO J. 16: 659-671.

Lee, J.H. and Schöffl, F. 1996. An Hsp70 antisense gene affects the expression of HSP70/HSC70, the regulation of HSF, and the acquisition of thermotolerance in transgenic Arabidopsis thaliana. Mol. Gen. Genet. 252: 11-19.

Lee, J.H., Hubel, A., and Schöffl, F. 1995. Derepression of the activity of genetically engineered heat shock factor causes constitutive synthesis of heat shock proteins and increased thermotolerance in transgenic Arabidopsis. Plant J. 8: 603-612.

Lipardi, C., Wei, Q., and Paterson, B. M. 2001. RNAi as random degradative PCR: siRNA primers convert mRNA into dsRNAs that are degraded to generate new siRNAs. Cell 107: 297-307.

Löw, D., Nover, L., and Forreiter, C. 2000. Cloning of cDNAs encoding cytosolic tomato Hsps Hsp17,7 class I and Hsp17,3 class II and their functional characterization as molecular chaperones in vivo. Planta 211: 575-582.

Lyck, R., Harmening, U., Höhfeld, I., Treuter, E., Scharf, K.-D., and Nover, L. 1997. Intracellular distribution and identification of the nuclear localization signals of two plant heatstress transcription factors. Planta 202: 117-125.

Malik, M.K., Slovin, J.P., Hwang, C.H., and Zimmerman, J.L. 1999. Modified expression of a carrot small heat shock protein gene, hsp17.7, results in increased or decreased thermotolerance double dagger. Plant I. 20: 89-99.

Meins, Jr., F. 2000. RNA degradation and models for post-transcriptional gene silencing. Plant Mol. Biol. 43: 261-273.

Morimoto, R.I. 1998. Regulation of the heat shock transcriptional response: Cross talk between family of heat shock factors, molecular chaperones, and negative regulators. Genes \& Dev. 12: 3788-3796.

Neumann, D., Scharf, K.-D., and Nover, L. 1984. Heat shock induced changes of plant cell ultrastructure and autoradiographic localization of heat shock proteins. Eur. J. Cell Biol. 34: 254-264.

Neumann, D., zur Nieden, U., Manteuffel, R., Walter, G.,
Scharf, K.-D., and Nover, L. 1987. Intracellular localization of heat shock proteins in tomato cells cultures. Eur. J. Cell Biol. 43: 71-81.

Nover, L. 1987. Expression of heat shock genes in homologous and heterologous systems. Enzyme Microb. Technol. 9: 130144.

Nover, L., Scharf, K.-D., and Neumann, D. 1983. Formation of cytoplasmic heat shock granules in tomato cell cultures and leaves. Mol. Cell. Biol. 3: 1648-1655.

-1989. Cytoplasmic heat shock granules are formed from precursor particles and are associated with a specific set of mRNAs. Mol. Cell. Biol. 9: 1298-1308.

Nover, L., Bharti, K., Döring, P., Mishra, S.K., Ganguli, A., and Scharf, K.-D. 2001. Arabidopsis and the heat stress transcription factor world: How many heat stress transcription factors do we need? Cell Stress Chaperones 6: 177-189.

Pelham, H.R.B. 1982. A regulatory upstream promoter element in the Drosophila hsp70 heat-shock gene. Cell 30: 517-528.

Pelham, H.R.B. and Bienz, M. 1982. A synthetic heat-shock promoter element confers heat-inducibility on the Herpes simplex virus thymidine kinase gene. EMBO J. 1: 1473-1477.

Queitsch, C., Hong, S.-W., Vierling, E., and Lindquist, S. 2000. Heat shock protein 101 plays a crucial role in thermotolerance in Arabidopsis. Plant Cell 12: 479-492.

Reichel, C., Mathur, J., Eckes, P., Langenkemper, K., Koncz, C., Schell, J., Reis, B., and Maas, C. 1996. Enhanced green fluorescence by the expression of an Aequorea victoria green fluorescent protein mutant in mono- and dicotyledonous plant cells. Proc. Natl. Acad. Sci. 93: 5888-5893.

Richter, K. and Buchner, J. 2001. Hsp90: Chaperoning signal transduction. J. Cell. Physiol. 188: 281-290.

Sambrook, J. and Russell, D.W. 2001. Molecular cloning: A laboratory manual, 3rd ed. Cold Spring Harbor Laboratory Press, Cold Spring Harbor, NY.

Scharf, K.-D., Rose, S., Zott, W., Schöffl, F., and Nover, L. 1990. Three tomato genes code for heat stress transcription factors with a region of remarkable homology to the DNA-binding domain of the yeast HSF. EMBO J. 9: 4495-4501.

Scharf, K.-D., Rose, S., Thierfelder, J., and Nover, L. 1993. Two cDNAs for tomato heat stress transcription factors. Plant Physiol. 102: 1355-1356.

Scharf, K.-D., Heider, H., Höhfeld, I., Lyck, R., Schmidt, E., and Nover, L. 1998. The tomato Hsf system: HsfA2 needs interaction with HsfAl for efficient nuclear import and may be localized in cytoplasmic heat stress granules. Mol. Cell. Biol. 18: $2240-2251$.

Severin, K., Wagner, A., and Schöffl, F. 1995. A heat-inducible Adh gene as a reporter for a negative selection in transgenic Arabidopsis. Transgenic Res. 4: 163-172.

Sharp, P.A. 2001. RNA interference-2001. Genes \& Dev. 15: 485-490.

Sheng, J. and Citovsky, V. 1996. Agrobacterium-plant cell DNA transport: Have virulence proteins, will travel. Plant Cell 8: 1699-1710.

Töpfer, R., Schell, J., and Steinbiss, H.H. 1988. Versatile cloning vectors for transient gene expression and direct gene transfer in plant cells. Nucleic Acids Res. 16: 8725.

Treuter, E., Nover, L., Ohme, K., and Scharf, K.-D. 1993. Promoter specificity and deletion analysis of three heat stress tran scription factors of tomato. Mol. Gen. Genet. 240: 113-125.

Wolters, A.-M.A. and Visser, R.G.F. 2000. Gene silencing in potato: Allelic differences and effect of ploidy. Plant Mol. Biol. 43: 377-386.

Wu, C. 1995. Heat stress transcription factors. Annu. Rev. Cell Biol. 11: 441-469. 


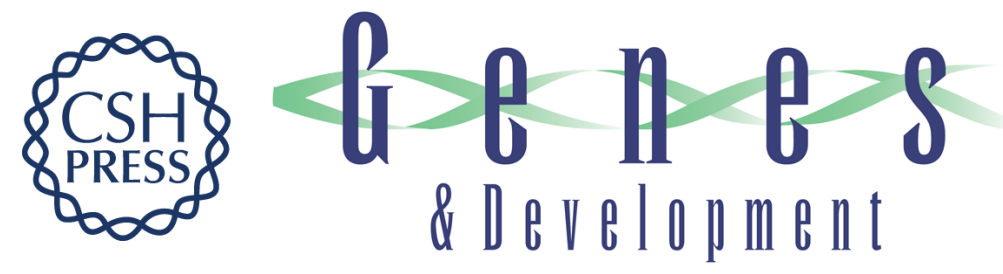

\section{In the complex family of heat stress transcription factors, HsfA1 has a unique role as master regulator of thermotolerance in tomato}

Shravan Kumar Mishra, Joanna Tripp, Sybille Winkelhaus, et al.

Genes Dev. 2002, 16:

Access the most recent version at doi:10.1101/gad.228802

References This article cites 53 articles, 19 of which can be accessed free at: http://genesdev.cshlp.org/content/16/12/1555.full.html\#ref-list-1

License

Email Alerting

Receive free email alerts when new articles cite this article - sign up in the box at the top Service right corner of the article or click here.

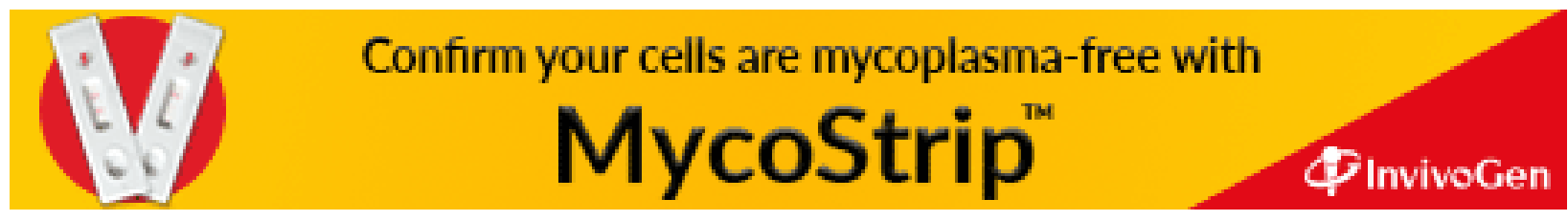

